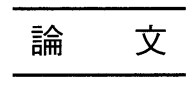

\title{
部分空間同定法に基づいた線形時変確率システムの 予測とその逐次アルゴリズム*
}

\author{
亀山建太郎 ${ }^{\dagger} \cdot$ 大住 $\quad$ 晃 $^{\dagger}$
}

\author{
Prediction of Linear Time-varying Stochastic Systems based on \\ the Subspace Identification Method and its Recursive \\ Algorithm*
}

\author{
Kentaro KAMEYAmA $^{\dagger}$ and Akira Ohsumi ${ }^{\dagger}$
}

In this paper, a prediction method is newly proposed for time-varying stochastic linear systems in the subspace identification framework. The key to this subspace-based prediction is to regard the change of the extended observability matrix yielded by the time-varying parameters of system as the rotation of the principal vectors that span the basis of the signal subspace. The rotation rate is evaluated from the angle between the past and current signal subspaces, and the future signal subspace is predicted by rotating the current subspace. A recursive algorithm is derived and its efficacy is tested by simulation experiments.

\section{1. 緒 言}

90 年代初頭に提案された部分空間同定法は, 実験に よって得られる同定対象の入出力データに基づいて, 最 小 2 乗法などにより伝達関数モデルのパラメータを推 定するというそれまでのモデリング法に対して，入出力 データから構成される代数関係式から, LQ 分解と特異 值分解を用いて，複雑な最適化計算を行うことなしに多 入力多出力システムの次元をも含めた同定を行うという 新しいシステム同定法である [1-3]. このシステム同定法 は，ここ十数年来活発な研究が行われてきている．当初 提案された部分空間同定法は線形離散時間時不変システ ムに対するものであり，これを連続時間システム [4,5]や 非線形性を有するシステム $[6]$ ，あるいは部分空間同定ア ルゴリズムの逐次化 [7-12] や時変システムへの適用 [13], さらにシステム変化の検出 [14] や実在システムへの応 用 [15] など多岐にわたっており，部分空間法の予測制御 への応用についても関心が高まってきている $[16,17]$.

とりわけ制御応用においては, 対象とするシステムが 時不変であれば，同定值が安定する值を用いてシステム 同定が完了し，その值をもって制御を行えばよいが，シ

* 原稿受付 2005 年 4 月 7 日

†京都工芸繊維大学 大学院 工芸科学研究科 Department of Mechanical \& System Engineering, Graduate School of Science and Technology, Kyoto Instutute of Technology; Matsugasaki, Sakyo, Kyoto 606-8585, JAPAN

Key Words: prediction, subspace identification, recursive algorithm, stochastic system, time-varying system.
ステムが時変である場合にはシステムマトリクスがどの ように変化していくのかを逐次同定し, さらに高精度の 制御を必要とするならば, システムの予測が必要となる. たとえば, 近年研究対象となっている複雑な化学プラン トなどの予測制御に, システムパラメータの変動を考慮 しない従来の部分空間同定法をそのまま適用する [17]の は適切でないのは明らかであり, 当然システムの予測と いう観点からそのような問題をとらえなければならない と思われる. 本研究は, この予測制御への適用をその最 終的な目的として部分空間同定法のシステム予測への拡 張を目指すものである。

\section{2. 問題の定式化}

対象とするシステムに対しては入出力データ $\left\{u_{k}, v_{k}\right\}$ のみが観測可能であり, その数学モデルは線形時変状態 空間モデル

$$
\begin{aligned}
x_{k+1} & =A_{k} x_{k}+B_{k} u_{k}+w_{k} \\
y_{k} & =C_{k} x_{k}+D_{k} u_{k}+v_{k}
\end{aligned}
$$

で表すことができるとする。ここで $u_{k} \in R^{m}, y_{k} \in R^{\ell}$ と $x_{k} \in R^{n}$ はそれぞれ入力, 出力および状態べクトルであ り, $w_{k} \in R^{n}$ と $v_{k} \in R^{\ell}$ は平均零, 共分散行列が

$$
\begin{array}{r}
\mathcal{E}\left\{\left[\begin{array}{l}
w_{k} \\
v_{k}
\end{array}\right]\left[\begin{array}{ll}
w_{s}^{\mathrm{T}} & v_{s}^{\mathrm{T}}
\end{array}\right]\right\}=\left[\begin{array}{cc}
Q & S \\
S^{\mathrm{T}} & R
\end{array}\right] \delta_{k s} \\
\left(\delta_{k s}: \text { クロネッカデルタ }\right)
\end{array}
$$


で与えられる正規性白色雑音とする．ただし，次元 $n$ は 既知であり，マトリクス $Q ， S ， R$ は定数とする。本モ デルにおける未知パラメータは, システムマトリクス $\left(A_{k}, B_{k}, C_{k}, D_{k}\right)$ である.

$k_{1}, k_{2}\left(k_{1}<k_{2}\right)$ をそれぞれ過去のある時点および 現在時点とし， $k_{1}, k_{2}$ よりそれぞれ $N+\alpha-2$ 時点過 去にさかのぼった時間区間 $\left[k_{1}-N-\alpha+2, k_{1}\right]$ および $\left[k_{2}-N-\alpha+2, k_{2}\right]$ 内に得られている入出力データによ りブロックハンケルマトリクス

$$
\begin{aligned}
& Y_{\alpha}\left(k_{\nu} \mid k_{\nu}-N+1\right)= \\
& {\left[\begin{array}{cccc}
y_{k_{\nu}-N-\alpha+2} & y_{k_{\nu}-N-\alpha+3} & \cdots & y_{k_{\nu}-\alpha+1} \\
y_{k_{\nu}-N-\alpha+3} & y_{k_{\nu}-N-\alpha+4} & \cdots & y_{k_{\nu}-\alpha+2} \\
\vdots & \vdots & & \vdots \\
y_{k_{\nu}-N+1} & y_{k_{\nu}-N+2} & \cdots & y_{k_{\nu}}
\end{array}\right] \in R^{\alpha \ell \times N}} \\
&
\end{aligned}
$$

を構成する. $\alpha$ と $N$ はそれぞれブロック行数, ブロック 列数である. $Y_{\alpha}\left(k_{1} \mid k_{1}-N+1\right)$ と $Y_{\alpha}\left(k_{2} \mid k_{2}-N+1\right)$ は 一部そのデー夕が重複しても理論的には何ら問題はない.

このとき, システムマトリクス $\left(A_{k}, B_{k}, C_{k}, D_{k}\right)$ の変 化は緩やかで突発的な変化をしないという仮定（quasistationarity assumption）[11-13]のもとで部分空間同 定法の基礎となる入出力代数方程式は

$$
\begin{gathered}
Y_{\alpha}\left(k_{\nu} \mid k_{\nu}-N+1\right)=\Gamma_{\alpha}\left(k_{\nu}\right) X_{\alpha}\left(k_{\nu} \mid k_{\nu}-N+1\right) \\
+H_{\alpha}\left(k_{\nu}\right) U_{\alpha}\left(k_{\nu} \mid k_{\nu}-N+1\right) \\
\quad+\Sigma_{\alpha}\left(k_{\nu}\right) W_{\alpha}\left(k_{\nu} \mid k_{\nu}-N+1\right) \\
\quad+V_{\alpha}\left(k_{\nu} \mid k_{\nu}-N+1\right) \quad(\nu=1,2)
\end{gathered}
$$

と得ることができる.ここで $\Gamma_{\alpha}(\cdot) \in R^{\alpha \ell \times n}$ は拡大可 観測マトリクス， $H_{\alpha}(\cdot)$ と $\Sigma_{\alpha}(\cdot)$ はシステムマトリクス $\left(A_{k_{\nu}}, B_{k_{\nu}}, C_{k_{\nu}}, D_{k_{\nu}}\right)$ から構成される下三角ブロックマト リクスである。すなわち

$$
\begin{aligned}
\Gamma_{\alpha}\left(k_{\nu}\right)= & {\left[\begin{array}{cccc}
C_{k_{\nu}}^{\mathrm{T}}\left(C_{k_{\nu}} A_{k_{\nu}}\right)^{\mathrm{T}} & \cdots & \left(C_{k_{\nu}} A_{k_{\nu}}^{\alpha-1}\right)^{\mathrm{T}}
\end{array}\right]^{\mathrm{T}} } \\
H_{\alpha}\left(k_{\nu}\right)= & {\left[\begin{array}{cccc}
D_{k_{\nu}} & 0 & \cdots & 0 \\
C_{k_{\nu}} B_{k_{\nu}} & D_{k_{\nu}} & & 0 \\
\vdots & \vdots & \ddots & \vdots \\
C_{k_{\nu}} A_{k_{\nu}}^{\alpha-2} B_{k_{\nu}} & C_{k_{\nu}} A_{k_{\nu}}^{\alpha-3} B_{k_{\nu}} & \cdots & D_{k_{\nu}}
\end{array}\right] } \\
\Sigma_{\alpha}\left(k_{\nu}\right)= & {\left[\begin{array}{cccc}
0 & 0 & \cdots & 0 \\
C_{k_{\nu}} & 0 & \cdots & 0 \\
C_{k_{\nu}} A_{k_{\nu}} & C_{k_{\nu}} & & 0 \\
\vdots & \vdots & \ddots & \vdots \\
C_{k_{\nu}} A_{k_{\nu}}^{\alpha-2} & C_{k_{\nu}} A_{k_{\nu}}^{\alpha-3} & \cdots & 0
\end{array}\right] }
\end{aligned}
$$

また $X_{\alpha}(\cdot \mid \cdot) \in R^{n \times N}$ は状態量から構成されるマトリク 久, $U_{\alpha}(\cdot \mid \cdot) \in R^{\alpha m \times N}, W_{\alpha}(\cdot \mid \cdot) \in R^{\alpha n \times N}, V_{\alpha}(\cdot \mid \cdot) \in$
$R^{\alpha \ell \times N}$ はそれぞれ $Y_{\alpha}(\cdot \mid \cdot)$ と同じ構造をもつ, 入力, シ ステム雑音, 観測雑音から構成されるマトリクスである [1-3].

本論文の目的は，現在時刻 $k_{2}$ までの入出力デー夕に 基づき，未来のある時点 $k_{3}\left(k_{2}<k_{3}\right)$ の未知パラメー夕 $\left(A_{k_{3}}, B_{k_{3}}, C_{k_{3}}, D_{k_{3}}\right)$ を予測するアルゴリズムを導出する ことであるが，部分空間同定アルゴリズムは，まず入出 カデータ $\left\{u_{k}, y_{k}\right\}$ より構成されるデータマトリクス $Y_{\alpha}$, $U_{\alpha}$ より，拡大可観測マトリクス $\Gamma_{\alpha}\left(k_{\nu}\right)$ の列ベクトル の張る空間 $\operatorname{span}_{\mathrm{col}}\left\{\Gamma_{\alpha}\left(k_{\nu}\right)\right\}$ (これを信号部分空間とよ ぶ [9]）を同定し，その結果を用いて各未知パラメータを 同定するアルゴリズムである点に注目すると, 未知パラ メータの予測という目的は，信号部分空間の予測という 問題に置き換えることができる。一方，時変パラメータ の変化に伴い拡大可観測マトリクス $\Gamma_{\alpha}\left(k_{\nu}\right)$ は変化する が，その時間変化を信号部分空間 $\operatorname{span}_{\mathrm{col}}\left\{\Gamma_{\alpha}\left(k_{\nu}\right)\right\}$ の基 底の回転ととらえることができるので，過去の信号部分 空間 $\operatorname{span}_{\mathrm{col}}\left\{\Gamma_{\alpha}\left(k_{1}\right)\right\}$ と現在のそれ $\operatorname{span}_{\mathrm{col}}\left\{\Gamma_{\alpha}\left(k_{2}\right)\right\}$ の 関係から信号部分空間の回転速度を求めることにより, 未来のある時点 $k_{3}$ の信号部分空間 $\operatorname{span}_{\mathrm{col}}\left\{\Gamma_{\alpha}\left(k_{3}\right)\right\}$ を 予測することが可能となる。

以上より，部分空間予測アルゴリズムはつぎのように 定式化することができる：

(i) 現在時刻 $k_{2}$ までの入出力データを観測し,

(ii) 現在の信号部分空間 $\operatorname{span}_{\mathrm{col}}\left\{\Gamma_{\alpha}\left(k_{2}\right)\right\}$ を同定する.

(iii) 蓄積しておいた過去の信号部分空間 $\operatorname{span}_{\mathrm{col}}\left\{\Gamma_{\alpha}\left(k_{1}\right)\right\}$ との関係から信号部分空間の回転速度を計算し,

(iv) それらの結果を用いて未来の信号部分空間 $\operatorname{span}_{\mathrm{col}}\left\{\Gamma_{\alpha}\left(k_{3}\right)\right\}$ を予測する.

(1)-(2) 式に含まれる未知システムマトリクスは信号 部分空間より従来の部分空間法を用いて求めることがで きる。

本論文で提案する予測手法自体はオフラインアルゴリ ズムであるが, 対象とするシステムが時変であることと, さらに予測制御をも指向する際にはオンライン同定に適 した逐次アルゴリズムが望まれることからその導出をも 行う.

\section{3. 部分空間の間の角度とその回転 \\ 3.1 部分空間の間の角度}

本論文では未来の信号部分空間の予測を行うために 現在と過去の信号部分空間の間に定義される角度とい う概念を用いる．本節では，一般的なマトリクスの列べ クトルにより張られる部分空間の間の角度の定義を行 う $[2,18]$.

各マトリクスの階数が $\operatorname{rank} A=a_{d}, \operatorname{rank} B=b_{d}$ である $A \in R^{p \times r}$ と $B \in R^{q \times r}$ を考える. このとき, $\operatorname{span}_{\mathrm{col}}\{A\}$ と $\operatorname{span}_{\mathrm{col}}\{B\}$ の間の角度は, それぞれの部分空間の基底 をなす主べクトル $a_{i} \in \operatorname{span}_{\mathrm{col}}\{A\}\left(i=1,2, \cdots, a_{d}\right), b_{j} \in$ $\operatorname{span}_{\mathrm{col}}\{B\}\left(j=1,2, \cdots, b_{d}\right)$ のうち, ベクトル $a_{i}, b_{i}$ 間の 
角度 $\theta_{i}\left(i=1,2, \cdots, a_{d} \wedge b_{d}, 0 \leq \theta_{i}<\pi / 2\right)$ の組 $\left\{a_{i}, b_{i}, \theta_{i}\right\}$ により定義される。ここで $a_{d} \wedge b_{d}=\min \left(a_{d}, b_{d}\right)$ である.

定義: マトリクス $A \in R^{p \times r}, B \in R^{q \times r}$ それぞれの列べク トルの張る部分空間の単位ベクトル $a_{1}, b_{1}$ を，それらの 間の角度 $\theta_{1}$ が最小になるように選ぶ.つぎに 2 組目の単 位べクトルの組 $\left(a_{2}, b_{2}\right)$ を，それぞれが $a_{1}$ と $b_{1}$ に直交し， かつベクトル間の角度 $\theta_{2}$ が最小になるように選ぶ. 以上 の手順を $a_{d} \wedge b_{d}$ 回繰り返し, 主べクトル $\left\{a_{1}, \cdots, a_{a_{d} \wedge b_{d}}\right\}$, $\left\{b_{1}, \cdots, b_{a_{d} \wedge b_{d}}\right\}$ とべクトル $\left\{a_{i}, b_{i}\right\}$ 間の角度 $\theta_{i} \in[0, \pi / 2)$ を得る。これらをそれぞれの部分空間の主べクトルと主 角とよび, $\operatorname{span}_{\mathrm{col}}\{A\}$ と $\operatorname{span}_{\mathrm{col}}\{B\}$ 間に定義される部 分空間の角度を $\left\{a_{i}, b_{i}, \theta_{i}\right\}\left(i=1, \cdots, a_{d} \wedge b_{d}\right)$ により定義 する。

以上の定義による二つの部分空間の間の角度は特異値 分解

$$
A\left(A^{\mathrm{T}} A\right)^{\dagger} A^{\mathrm{T}} B\left(B^{\mathrm{T}} B\right)^{\dagger} B^{\mathrm{T}}=U S V^{\mathrm{T}}
$$

により計算することができる。ここで $U \in R^{p \times p}$ と $V \in$ $R^{q \times q}$ は正規直交マトリクス, $S \in R^{p \times q}$ は特異值 $\sigma_{i}(i=$ $\left.1, \cdots, a_{d} \wedge b_{d}\right)$ を対角要素に持つマトリクス, また†はムー ア・ペンローズの擬似逆マトリクスであり, $\operatorname{span}_{\mathrm{col}}\{A\}$ の主ベクトル $u_{j} \in R^{p}\left(j=1, \cdots, a_{d}\right)$ は $U\left(:, 1: a_{d}\right)$ の各 列ベクトルである（記号 $U(a: b, c: d)$ はマトリクス $U$ の 第 $a$ 行から第 $b$ 行と第 $c$ 列から第 $d$ 列までの要素を意味 し, $U(:, c: d)$ は $U$ の $c$ 列から $d$ 列のすべての行要素を 意味する). 同様に, $\operatorname{span}_{\mathrm{col}}\{B\}$ の主ベクトル $v_{j} \in R^{q}$ $\left(j=1,2, \cdots, b_{d}\right)$ \& $V\left(:, 1: b_{d}\right)$ の各列べクトルである.ま た, 主角 $\theta_{i}$ は特異值 $\sigma_{i}$ との関係

$$
\sigma_{i}=\cos \theta_{i} \quad\left(i=1,2, \cdots, a_{d} \wedge b_{d}\right)
$$

より求めることができる.

\section{2 部分空間の回転}

本節では，3.1 節で定義した二つの部分空間の間の角 度を用いて部分空間の回転を定義するが，この場合，部 分空間 $\operatorname{span}_{\mathrm{col}}\{A\}$ を回転させて $\operatorname{span}_{\mathrm{col}}\{B\}$ とするの で，任意の二つの部分空間の間の角度を求める場合とは 異なり, マトリクスのサイズと階数は一定と考えるのが 適切である. よって本節では, $p=q$ かつ $a_{d}=b_{d}$ の場合 について考える。また，前節において部分空間の間の角 度は各主べクトル間の角度の集合により定義されること を述べたが，部分空間の回転もまた主べクトルの回転の 集合により定式化される，各主べクトルの関係を回転作 用素 $\mathcal{R}_{\theta_{i}}$ を用い, $v_{i}=\mathcal{R}_{\theta_{i}} u_{i}$ と表すとすると, $\mathcal{R}_{\theta_{i}}$ はつ ぎの手順により求めることができる.

まず，主べクトル $u_{i}=\left[u_{i 1}, u_{i 2}, \cdots, u_{i p}\right]^{\mathrm{T}}$ と $v_{i}=\left[v_{i 1}\right.$ ， $\left.v_{i 2}, \cdots, v_{i p}\right]^{\mathrm{T}}$ の回転平面を考え, その正規直交基底を

$$
e_{i 1}:=\frac{u_{i}}{\left\|u_{i}\right\|^{2}}
$$

$$
e_{i 2}:=\frac{v_{i}-\left\langle v_{i}, e_{i 1}\right\rangle e_{i 1}}{\left\|v_{i}-\left\langle v_{i}, e_{i 1}\right\rangle e_{i 1}\right\|^{2}}
$$

と定義する.ここで $\langle a, b\rangle$ は $a$ と $b$ の内積 $a^{\mathrm{T}} b$ を表わす. 残りの基底べクトル $e_{i j} \in R^{p}(j=3, \cdots, p)$ は条件

$$
e_{i j} e_{i k}^{\mathrm{T}}=I_{p} \delta_{j k} \quad(j, k=1,2, \cdots, p)
$$

を満たすように任意に選ぶことができる $\left(I_{p} \in R^{p \times p}\right.$ : 単 位マトリクス). すなわち $\left\{e_{i 1}, e_{i 2}, e_{i 3}, \cdots, e_{i p}\right\}$ は $R^{p}$ 次 元ベクトル空間の正規直交基底をなし, $\left\{e_{i 1}, e_{i 2}\right\}$ は $R^{p}$ に含まれる回転平面の正規直交基底である。これらの基 底を用いると， $u_{i}$ と $v_{i}$ はそれぞれ

$$
\begin{aligned}
u_{i} & =a_{i 1} e_{i 1}+a_{i 2} e_{i 2}+\cdots+a_{i p} e_{i p} \\
& =a_{i 1} e_{i 1} \\
v_{i} & =b_{i 1} e_{i 1}+b_{i 2} e_{i 2}+\cdots+b_{i p} e_{i p} \\
& =b_{i 1} e_{i 1}+b_{i 2} e_{i 2}
\end{aligned}
$$

と表現できる。ただし $a_{i j}=\left\langle u_{i}, e_{i j}\right\rangle, b_{i j}=\left\langle v_{i}, e_{i j}\right\rangle(j=$ $1,2, \cdots, p), a_{i 2}=\cdots=a_{i p}=0, b_{i 3}=\cdots=b_{i p}=0$ である. また $a_{i j}$ と $b_{i j}(j=1,2)$ の関係は

$$
\left[\begin{array}{l}
b_{i 1} \\
b_{i 2}
\end{array}\right]=\left[\begin{array}{rr}
\cos \theta_{i} & -\sin \theta_{i} \\
\sin \theta_{i} & \cos \theta_{i}
\end{array}\right]\left[\begin{array}{l}
a_{i 1} \\
a_{i 2}
\end{array}\right]
$$

であり，(9)，(11) 式を(10) 式に代入すると

$$
\begin{aligned}
v_{i} & =\left[\begin{array}{ll}
e_{i 1} & e_{i 2}
\end{array}\right]\left[\begin{array}{rrr}
\cos \theta_{i} & -\sin \theta_{i} \\
\sin \theta_{i} & \cos \theta_{i}
\end{array}\right]\left[\begin{array}{l}
a_{i 1} \\
a_{i 2}
\end{array}\right] \\
& {\left[\begin{array}{lllll}
e_{i 1} & e_{i 2} & e_{i 3} & \cdots & e_{i p}
\end{array}\right] } \\
& {\left[\begin{array}{ccccc}
\cos \theta_{i} & -\sin \theta_{i} & 0 & \cdots & 0 \\
\sin \theta_{i} & \cos \theta_{i} & 0 & \cdots & 0 \\
0 & 0 & 1 & \cdots & 0 \\
\vdots & \vdots & \vdots & \ddots & \vdots \\
0 & 0 & 0 & \cdots & 1
\end{array}\right]\left[\begin{array}{c}
a_{i 1} \\
a_{i 2} \\
a_{i 3} \\
\vdots \\
a_{i p}
\end{array}\right] } \\
& {\left[\begin{array}{ccccc}
e_{i 1} & e_{i 2} & e_{i 3} & \cdots & e_{i p}
\end{array}\right] } \\
& {\left[\begin{array}{ccccc}
\cos \theta_{i} & -\sin \theta_{i} & 0 & \cdots & 0 \\
\sin \theta_{i} & \cos \theta_{i} & 0 & \cdots & 0 \\
0 & 0 & 1 & \cdots & 0 \\
\vdots & \vdots & \vdots & \ddots & \vdots \\
0 & 0 & 0 & \cdots & 1
\end{array}\right]\left[\begin{array}{c}
e_{i 1}^{\mathrm{T}} \\
e_{i 2}^{\mathrm{T}} \\
e_{i 3}^{\mathrm{T}} \\
\vdots \\
e_{i p}^{\mathrm{T}}
\end{array}\right] u_{i} }
\end{aligned}
$$

の関係を得る。よってこれを用いると $\operatorname{span}_{\mathrm{col}}\{B\}$ と $\operatorname{span}_{\mathrm{col}}\{A\}$ の関係は

$\operatorname{span}_{\text {col }}\left\{\left[v_{1} \cdots v_{a_{d}}\right]\right\}=\operatorname{span}_{\text {col }}\left\{\left[\mathcal{R}_{\theta_{1}} u_{1} \cdots \mathcal{R}_{\theta_{a_{d}}} u_{a_{d}}\right]\right\}$

と表すことができる。 


\section{4. 部分空間の予測}

\section{1 部分空間予測アルゴリズム}

$k_{1}, k_{2}, k_{3}$ をそれぞれ過去, 現在, そして未来のあ る時点 $\left(k_{1}<k_{2}<k_{3}\right)$ とし， $k_{2}$ までの入出力データが 観測されている状況において，システムマトリクス $\left(A_{k}, B_{k}, C_{k}, D_{k}\right)$ の時刻 $k_{3}$ における予測值を求める．時 刻 $k=k_{\nu}(\nu=1,2)$ における拡大可観測マトリクス

$$
\begin{aligned}
& \Gamma_{\alpha}\left(k_{\nu}\right)=\left[C_{k_{\nu}}^{\mathrm{T}}\left(C_{k_{\nu}} A_{k_{\nu}}\right)^{\mathrm{T}} \cdots\left(C_{k_{\nu}} A_{k_{\nu}}{ }^{\alpha-1}\right)^{\mathrm{T}}\right]^{\mathrm{T}} \\
& (\nu=1,2)
\end{aligned}
$$

は入出力データより同定することができる.一方，これ らのマトリクスを

$$
\Gamma_{\alpha}\left(k_{\nu}\right)=\left[\gamma_{1}\left(k_{\nu}\right) \gamma_{2}\left(k_{\nu}\right) \cdots \gamma_{n}\left(k_{\nu}\right)\right]
$$

と列ベクトル $\left\{\gamma_{1}\left(k_{\nu}\right), \cdots, \gamma_{n}\left(k_{\nu}\right)\right\}$ により記述し，これ らを基底とする信号部分空間 $\operatorname{span}_{\mathrm{col}}\left\{\Gamma_{\alpha}\left(k_{\nu}\right)\right\}$ を考える と, $\Gamma_{\alpha}\left(k_{\nu}\right)$ は時変パラメータより構成されているため時 間とともに変化するので, $(15)$ 式よりこの変化を信号部 分空間の基底をなす主べクトル $\left\{\gamma_{1}\left(k_{\nu}\right), \cdots, \gamma_{n}\left(k_{\nu}\right)\right\}$ の回 転とみなすことができる，すなわち $\gamma_{i}(\cdot) \in R^{\alpha \ell}$ より，過 去と現在の信号部分空間 $\Gamma_{\alpha}\left(k_{1}\right), \Gamma_{\alpha}\left(k_{2}\right)$ の違いは, 時 間間隔 $\left[k_{1}, k_{2}\right]$ における $\alpha \ell$ 次元べクトル空間における $n$ 次元信号部分空間の回転と考えることができる.

さて, $\operatorname{span}_{\mathrm{col}}\left\{\Gamma_{\alpha}\left(k_{1}\right)\right\}$ と $\operatorname{span}_{\mathrm{col}}\left\{\Gamma_{\alpha}\left(k_{2}\right)\right\}$ の関係は, 特異值分解

$$
\begin{gathered}
\Gamma_{\alpha}\left(k_{1}\right)\left\{\Gamma_{\alpha}^{\mathrm{T}}\left(k_{1}\right) \Gamma_{\alpha}\left(k_{1}\right)\right\}^{\dagger} \Gamma_{\alpha}^{\mathrm{T}}\left(k_{1}\right) \\
\cdot \Gamma_{\alpha}\left(k_{2}\right)\left\{\Gamma_{\alpha}^{\mathrm{T}}\left(k_{2}\right) \Gamma_{\alpha}\left(k_{2}\right)\right\}^{\dagger} \Gamma_{\alpha}^{\mathrm{T}}\left(k_{2}\right) \\
=U\left(k_{1}\right) S\left(k_{1} \mid k_{2}\right) V^{\mathrm{T}}\left(k_{2}\right)
\end{gathered}
$$

により求まる主ベクトル

$$
\begin{aligned}
& U\left(k_{1}\right)(:, 1: n)=\left[\begin{array}{lll}
\gamma_{1}\left(k_{1}\right) & \cdots & \gamma_{n}\left(k_{1}\right)
\end{array}\right] \\
& V\left(k_{2}\right)(:, 1: n)=\left[\begin{array}{lll}
\gamma_{1}\left(k_{2}\right) & \cdots & \gamma_{n}\left(k_{2}\right)
\end{array}\right]
\end{aligned}
$$

と, 特異值 $\left\{\sigma_{i}\left(k_{2} \mid k_{1}\right)\right\}$ との関係

$$
\sigma_{i}\left(k_{2} \mid k_{1}\right)=\cos \theta_{i}\left(k_{2} \mid k_{1}\right)
$$

より求まる回転角度 $\left\{\theta_{i}\left(k_{2} \mid k_{1}\right)\right\}(i=1, \cdots, n)$ を $(12)$ お よび (13) 式に適用することにより記述できる. 時間差 $k_{2}-k_{1}$ については，つぎのことに留意する必要がある. すなわち, 特異值分解により得られるべクトルと相対 角度のすべての組 $\left(\gamma_{i}\left(k_{1}\right), \gamma_{i}\left(k_{2}\right), \theta_{i}\left(k_{2} \mid k_{1}\right)\right)$ が, “ベクト ル $\gamma_{i}\left(k_{1}\right)$ が $k_{2}-k_{1}$ 時間内で $\theta_{i}\left(k_{2} \mid k_{1}\right)$ 回転して $\gamma_{i}\left(k_{2}\right)$ になった”という意味をもつように，時間差 $k_{2}-k_{1}$ を $\gamma_{i}\left(k_{1}\right)$ と $\gamma_{i}\left(k_{2}\right)$ との間の角度 $\theta_{j i}\left(k_{2} \mid k_{1}\right)(i \neq j)$ に対し て $\theta_{i}\left(k_{2} \mid k_{1}\right)<\theta_{j i}\left(k_{2} \mid k_{1}\right)$ となるように十分小さくとる.

ここで，時間間隔 $\left[k_{1}, k_{3}\right]$ における回転速度が一定で あると仮定すれば，時間間隔 $\left[k_{2}, k_{3}\right]$ における主べクト
ルの回転角度は

$$
\hat{\theta}_{i}\left(k_{3} \mid k_{2}\right)=\Delta \theta_{i}\left(k_{2} \mid k_{1}\right)\left(k_{3}-k_{2}\right)
$$

で与えられる。ここで， $\Delta \theta_{i}\left(k_{2} \mid k_{1}\right)$ は回転速度

$$
\begin{array}{r}
\Delta \theta_{i}\left(k_{2} \mid k_{1}\right)=\frac{\theta_{i}\left(k_{2} \mid k_{1}\right)}{k_{2}-k_{1}}+o\left(k_{3}-k_{2}\right) \\
{[\mathrm{rad} / \mathrm{step}]}
\end{array}
$$

であり, $o\left(k_{3}-k_{2}\right)$ は高次の誤差項である.

さらに, 回転が同一平面内で行われているという仮定 のもとで $\gamma_{i}\left(k_{3}\right)$ の予測值を

$$
\hat{\gamma}_{i}\left(k_{3} \mid k_{2}\right)=\mathcal{R}_{\hat{\theta}_{i}\left(k_{3} \mid k_{2}\right)} \gamma_{i}\left(k_{2}\right)
$$

として求めることができる.したがって，これより信号 部分空間の予測值を

$$
\begin{aligned}
& \operatorname{span}_{\operatorname{col}}\left\{\hat{\Gamma}_{\alpha}\left(k_{3} \mid k_{2}\right)\right\} \\
& \quad=\operatorname{span}_{\text {col }}\left\{\left[\hat{\gamma}_{1}\left(k_{3} \mid k_{2}\right) \cdots \hat{\gamma}_{n}\left(k_{3} \mid k_{2}\right)\right]\right\}
\end{aligned}
$$

と得る.

よって，この予測された拡大可観測マトリクスに従来 の部分空間同定法 [1-3] を適用すれば, 時刻 $k=k_{3}$ におけ るシステムマトリクス $\left(A_{k}, B_{k}, C_{k}, D_{k}\right)$ が同定できる.

\section{2 高次微分を考慮した予測アルゴリズム}

前節では，各主ベクトルの回転が一定であるとして部 分空間予測アルゴリズムを導出した。この仮定は主べク トルの回転速度の変化が小さいシステムに対しては適切 であるが，回転速度が変動する場合もあろう．そのよう なシステムへの対処法として, 回転速度の高次の導関数 が一定であるという仮定も意味を持つ。一例として，回 転加速度が一定とした場合について述べる。

この場合には， 4 時刻 $k_{0}<k_{1}<k_{2}<k_{3}$ を考える.わ れわれの目的は現在時刻 $k_{2}$ までの入出力デー夕を用い て $\Gamma_{i}\left(k_{3}\right)$ を予測することであるが，これは $\left[k_{2}, k_{3}\right] に お ~$ ける回転角度 $\theta_{i}\left(k_{3} \mid k_{2}\right)$ の予測にほかならない. 仮定よ $\eta$, 時間間隔 $\left[k_{0}, k_{2}\right]$ と $\left[k_{1}, k_{3}\right]$ それぞれにおける角加速 度が等しい, すなわち関係式

$$
\frac{\Delta \theta_{i}\left(k_{2} \mid k_{1}\right)-\Delta \theta_{i}\left(k_{1} \mid k_{0}\right)}{\Delta k}=\frac{\Delta \hat{\theta}_{i}\left(k_{3} \mid k_{2}\right)-\Delta \theta_{i}\left(k_{2} \mid k_{1}\right)}{\left(k_{3}-k_{2}\right) / 2+\Delta k / 2}
$$

が成り立つので，これを $\hat{\theta}_{i}\left(k_{3} \mid k_{2}\right)$ について解き

$$
\begin{gathered}
\hat{\theta}_{i}\left(k_{3} \mid k_{2}\right)=\frac{\theta_{i}\left(k_{2} \mid k_{1}\right)}{2}\left\{\left(\frac{k_{3}-k_{2}}{\Delta k}\right)^{2}+3\left(\frac{k_{3}-k_{2}}{\Delta k}\right)\right\} \\
-\frac{\theta_{i}\left(k_{1} \mid k_{0}\right)}{2}\left\{\left(\frac{k_{3}-k_{2}}{\Delta k}\right)^{2}+\left(\frac{k_{3}-k_{2}}{\Delta k}\right)\right\}
\end{gathered}
$$

を得る。ここに， $\Delta k=k_{2}-k_{1}=k_{1}-k_{0}$ である.これを (12) 式と (13) 式に適用することにより, 信号部分空間の 
予測值 $\hat{\Gamma}_{i}\left(k_{3}\right)$ を得る.

\section{5. 部分空間同定アルゴリズムの逐次化}

4 章で述べた予測手法は，あらかじめ求めておいた過去 と現在の信号部分空間の二つの推定值 $\hat{\Gamma}_{\alpha}\left(k_{\nu}\right)(\nu=1,2)$ を用いて未来の信号部分空間を求めるオフラインアルゴ リズムであるが，対象とするシステムが時変であること から逐次的に予測するアルゴリズムが望まれる。何より も予測制御を指向する際には, 計算機の記憶容量などの 観点からもそのようなアルゴリズムが強く望まれる。実 際, 逐次化しない部分空間予測アルゴリズムでは, 現在 時刻の信号部分空間の推定と, 過去と現在の信号部分空 間の間の角度を求める際に特異值分解が 2 度必要となり 圥長である。

本章では，逐次予測アルゴリズムを著者らが提案して いる逐次部分空間同定アルゴリズム $[11,12]$ の考え方を 用いて導出する. まず, マトリクスの LQ 分解

$$
\begin{gathered}
{\left[\begin{array}{l}
U_{\alpha}\left(k_{2} \mid k_{2}-N+1\right) \\
U_{\beta}\left(k_{2} \mid k_{2}-N+1\right) \\
Y_{\alpha}\left(k_{2} \mid k_{2}-N+1\right)
\end{array}\right]=} \\
{\left[\begin{array}{ccc}
L_{11}\left(k_{2}\right) & 0 & 0 \\
L_{21}\left(k_{2}\right) & L_{22}\left(k_{2}\right) & 0 \\
L_{31}\left(k_{2}\right) & L_{32}\left(k_{2}\right) & L_{33}\left(k_{2}\right)
\end{array}\right]\left[\begin{array}{l}
Q_{1}^{\mathrm{T}}\left(k_{2}\right) \\
Q_{2}^{\mathrm{T}}\left(k_{2}\right) \\
Q_{3}^{\mathrm{T}}\left(k_{2}\right)
\end{array}\right]}
\end{gathered}
$$

を考える.ここで $U_{\beta}(\cdot \mid \cdot)$ は $Y_{\alpha}(\cdot \mid \cdot)$ と同様の構造をも ち, 過去の入力デー夕から構成された補助変数マトリク スである (付録 1 参照). $L_{32}\left(k_{2}\right) L_{32}{ }^{\mathrm{T}}\left(k_{2}\right)$ は入出力デー 夕量を固定した逐次部分空間同定アルゴリズム $[11,12]$ (付録 1 参照) により更新され, $\operatorname{span}_{\mathrm{col}}\left\{\Gamma_{\alpha}\left(k_{2}\right)\right\} \subset$ $\operatorname{span}_{\text {col }}\left\{L_{32}\left(k_{2}\right) L_{32}{ }^{\mathrm{T}}\left(k_{2}\right)\right\}$ であるが, $L_{32}\left(k_{2}\right) L_{32}{ }^{\mathrm{T}}\left(k_{2}\right)$ は雑音の影響により数值的に正則となるため,このまま (16) 式に用いることはできない.そこで, つぎの手順に より信号部分空間を再構成する。

まず, $L_{32}\left(k_{2}\right)$ と $L_{32}\left(k_{2}\right) L_{32}^{\mathrm{T}}\left(k_{2}\right)$ を

$$
\begin{aligned}
L_{32}\left(k_{2}\right) & =\left[\begin{array}{llll}
s_{1}\left(k_{2}\right) & s_{2}\left(k_{2}\right) & \cdots & s_{\alpha \ell}\left(k_{2}\right)
\end{array}\right] \\
L_{32}\left(k_{2}\right) L_{32}{ }^{\mathrm{T}}\left(k_{2}\right) & =\left[\begin{array}{llll}
h_{1}\left(k_{2}\right) & h_{2}\left(k_{2}\right) & \cdots & h_{\alpha \ell}\left(k_{2}\right)
\end{array}\right]
\end{aligned}
$$

と列ベクトルにより記述する。さらに, $f_{i j}(\cdot)$ を $L_{32}{ }^{\mathrm{T}}\left(k_{2}\right)$ の第 $(i, j)$ 要素とすると $L_{32}\left(k_{2}\right) L_{32}{ }^{\mathrm{T}}\left(k_{2}\right)$ の列べクトルは

$$
\begin{array}{r}
h_{j}\left(k_{2}\right)=f_{1 j}\left(k_{2}\right) s_{1}\left(k_{2}\right)+f_{2 j}\left(k_{2}\right) s_{2}\left(k_{2}\right)+\cdots \\
+f_{\alpha \ell j}\left(k_{2}\right) s_{\alpha \ell}\left(k_{2}\right)(j=1, \cdots, \alpha \ell)
\end{array}
$$

と表現できる。このとき $h_{j}\left(k_{2}\right)(j=1,2, \cdots, \alpha \ell) ょ り n$ 本の列ベクトルを任意に選び，マトリクス

$$
L_{b}\left(k_{2}\right)=\left[h_{i}\left(k_{2}\right), \cdots, h_{j}\left(k_{2}\right)\right] \in R^{\alpha \ell \times n}(i \neq j)
$$

を構成すると, 定義より $L_{b}\left(k_{2}\right)$ は

$$
\begin{array}{r}
\operatorname{span}_{\mathrm{col}}\left\{\Gamma_{\alpha}\left(k_{2}\right)\right\} \subset \operatorname{span}_{\mathrm{col}}\left\{L_{b}\left(k_{2}\right)\right\} \\
\subset \operatorname{span}_{\mathrm{col}}\left\{L_{32}\left(k_{2}\right) L_{32}^{\mathrm{T}}\left(k_{2}\right)\right\}
\end{array}
$$

を満たすので, $\operatorname{span}_{\mathrm{col}}\left\{\Gamma_{\alpha}\left(k_{1}\right)\right\}$ と $\operatorname{span}_{\mathrm{col}}\left\{\Gamma_{\alpha}\left(k_{2}\right)\right\}$ の角 度は, 時刻 $k_{1}$ と $k_{2}$ の部分空間のなす角度が $\theta_{i}\left(k_{2} \mid k_{1}\right)<$ $\pi / 4$ である限りは， $\Gamma_{\alpha}\left(k_{1}\right)$ と $L_{b}\left(k_{2}\right)$ を用いて

$$
\begin{gathered}
\hat{\Gamma}_{\alpha}\left(k_{1}\right)\left\{\hat{\Gamma}_{\alpha}^{\mathrm{T}}\left(k_{1}\right) \hat{\Gamma}_{\alpha}\left(k_{1}\right)\right\}^{\dagger} \hat{\Gamma}_{\alpha}^{\mathrm{T}}\left(k_{1}\right) \\
\cdot L_{b}\left(k_{2}\right)\left\{L_{b}^{\mathrm{T}}\left(k_{2}\right) L_{b}\left(k_{2}\right)\right\}^{\dagger} L_{b}^{\mathrm{T}}\left(k_{2}\right) \\
=U\left(k_{1}\right) S\left(k_{1} \mid k_{2}\right) V^{\mathrm{T}}\left(k_{2}\right)
\end{gathered}
$$

と計算することができる (付録 2). 以上の考え方により， 逐次部分空間予測アルゴリズムは以下のようにまとめら れる:

[逐次部分空間予測アルゴリズム]

Step 1 入出力データ $\left\{u\left(k_{2}\right), y\left(k_{2}\right)\right\}$ を観測し, 逐次部分 空間同定アルゴリズム (付録 $\mathbf{1}$ ) に基づき $L_{32}\left(k_{2}\right)$. $L_{32}^{\mathrm{T}}\left(k_{2}\right)$ を更新する。

Step $2 L_{b}\left(k_{2}\right)$ を構成し, 特異值分解 $(28)$ により部分空 間の間の角度を求める。

Step 34 章で示した部分空間予測法により, 未来の信号 部分空間 $\hat{\Gamma}_{\alpha}\left(k_{3}\right)$ を予測する.

Step $4 \hat{\Gamma}_{\alpha}(\cdot)$ を用いて $\left(A_{k_{3}}, B_{k_{3}}, C_{k_{3}}, D_{k_{3}}\right)$ を導出する. $\overline{\text { Step } 5} k_{2} \rightarrow k_{2}+1$ として Step 1 に戻る.

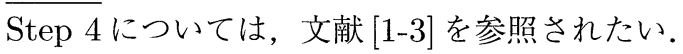

\section{6. 数值例}

$$
\begin{aligned}
& \text { システムマトリクスが } \\
& \qquad A_{k}=\frac{1}{2}\left[\begin{array}{cc}
\sin (2 \pi k / a), & 0.5+\sin (\pi k / 2 a) \\
-0.5-\sin (\pi k / 2 a), & \sin (\pi k / a)
\end{array}\right] \\
& B=\left[\begin{array}{r}
2.0 \\
-1.0
\end{array}\right], \quad C=[1.0,2.0], \quad D=1.5
\end{aligned}
$$

である 1 入力 1 出力 2 次元の線形離散時間時変シス テムを対象とした数值例により，提案アルゴリズムの 性質と有効性の検証を行う. 入力 $u_{k}$ は平均零, 分散 が $\mathcal{E}\left\{u_{k} u_{s}^{\mathrm{T}}\right\}=\delta_{k s}$, 雑音 $w_{k}$ と $v_{k}$ は平均零, 分散が $\mathcal{E}\left\{w_{k} w_{s}^{\mathrm{T}}\right\}=\mathcal{E}\left\{v_{k} v_{s}^{\mathrm{T}}\right\}=0.1^{2} \delta_{k s}$ の正規性白色雑音で あり，観測データマトリクスのブロック行数は $\alpha=\beta=5$ としている。また， $(26)$ 式の $L_{b}\left(k_{2}\right)$ の構成にあたって は, その要素べクトル $h_{j}\left(k_{2}\right)$ として最初の $n$ 個のベク トル $\left\{h_{j}\left(k_{2}\right), j=1,2, \cdots, n\right\}$ を用いた.

まず上記システムにおいて $a=1000$ とし, 1 回の 同定に用いるデータ幅を $N=75$, 予測ステップ数を $L\left(:=k_{3}-k_{2}\right)=50$ とした場合の予測結果を Fig. 1 に示 す。システム極の実部（上図），および虚部（下図）の 真值を破線で，また予測值を一点鎖線で示した。十分な 観測データが得られない初期の区間では予測值と真值の ずれが見られるが，その後は実部，虚部のいずれも予測 

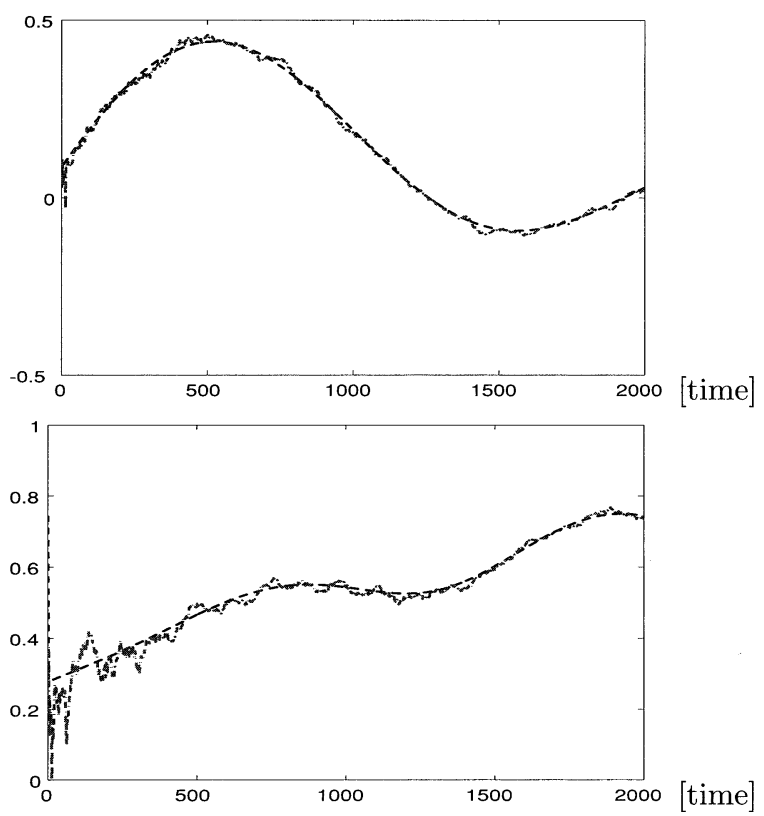

Fig. 1 Time evolutions of real (top) and imaginary (bottom) parts of predicted conjugate poles $(N=$ $75, L=50$ (50-step ahead prediction))
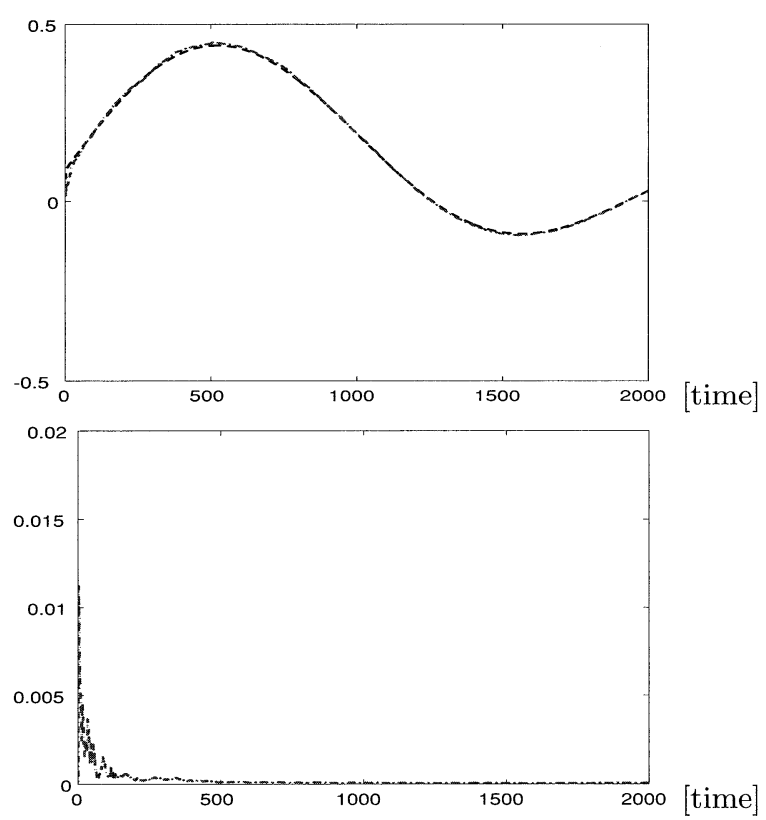

Fig. 2 Sample mean (top) and variance (bottom) of the real part of predicted conjugate poles $(N=75$, $L=0$ (Estimation))

值は真值の軌跡とよくあっている.

予測がどの程度首尾よく行われるかをみるために, Fig. 1 の場合と同一条件で, 予測ステップ数 $L$ のみを, $L=0$ (この場合は推定值に相当), $L=50, L=100$ としてシ ミュレーションを行い, それぞれの 50 回の試行平均の 結果をFigs. 2-4に示した. いずれの図においても上図 が予測值のサンプル平均值, 下図がサンプル分散值であ る.これらの図から，Lを大きく設定しても分散が著し く増大するということはなく，提案アルゴリズムにより
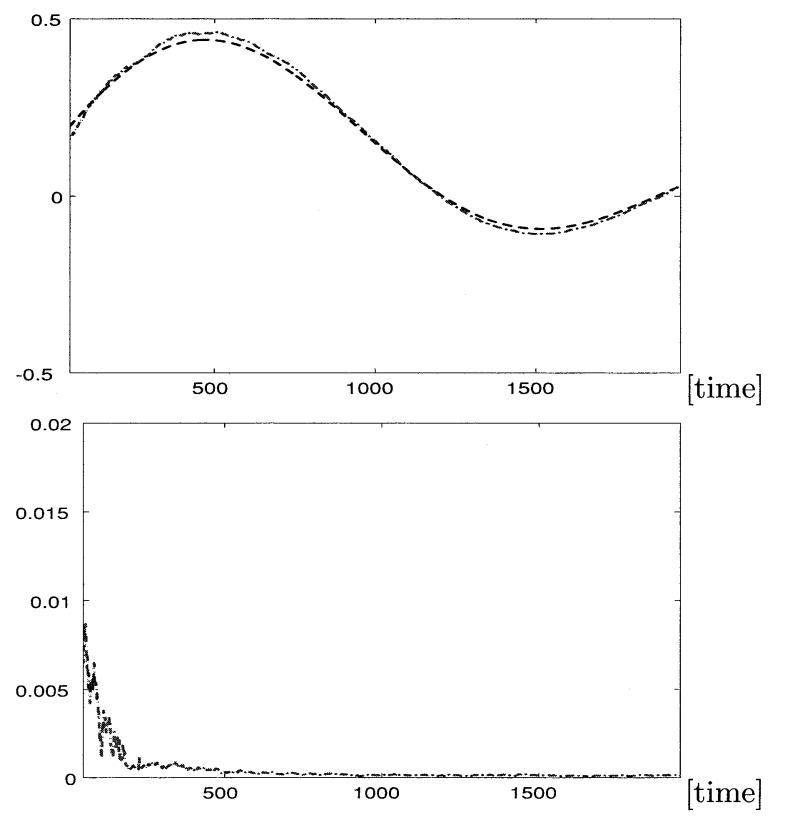

Fig. 3 Sample mean (top) and variance (bottom) of the real part of predicted conjugate poles $(N=75$, $L=50$ (50-step ahead prediction))
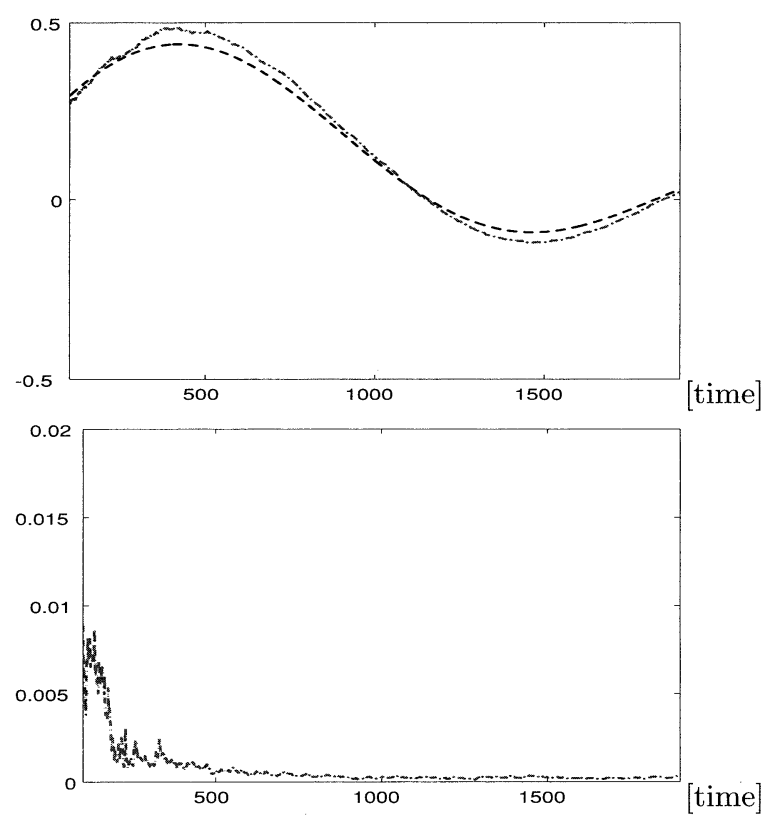

Fig. 4 Sample mean (top) and variance (bottom) of the real part of predicted conjugate poles $(N=75$, $L=100$ (100-step ahead prediction))

良い予測值が得られているということができる。

つぎに，信号部分空間の回転速度を一定と仮定したア ルゴリズム $(\S 4.1)$ と, その加速度を一定と仮定したアル ゴリズム $(\S 4.2)$ の比較を行った. Fig. 5 およびFig. 6 に $N=100$ とし, 予測ステップ数を $L=0$ と $L=150$ とし た場合のシステム極の実部の予測值を，回転速度一定と した場合の結果を一点鎖線で，回転加速度一定とした場 合のそれを点線で，また真值の軌跡を破線で示している. これらの図より，同じシステムを対象とした場合，シス 

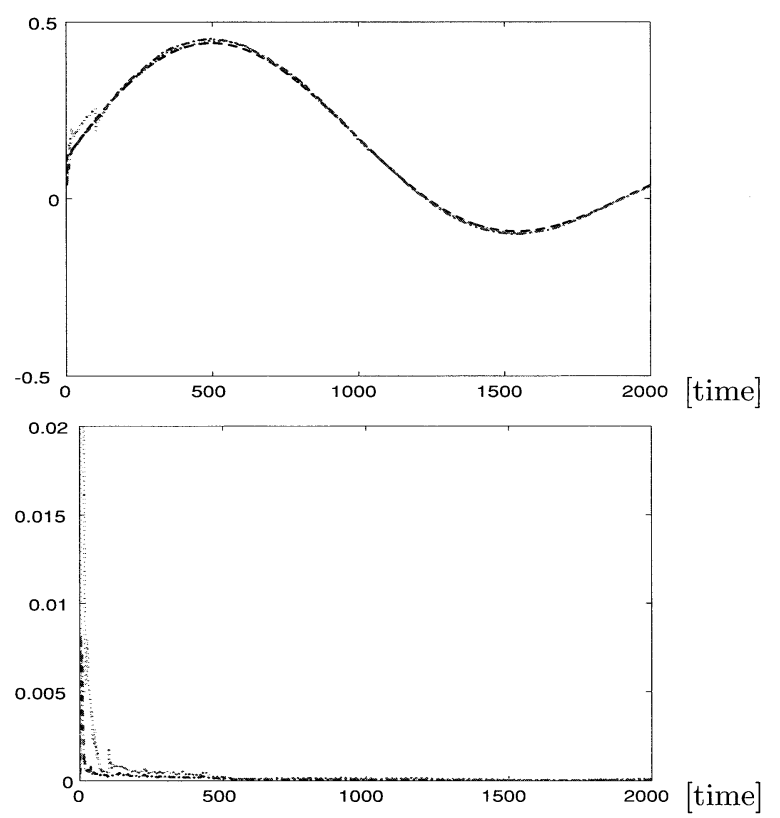

Fig. 5 Sample mean (top) and variance (bottom) of the real part of predicted conjugate poles $(N=100$, $L=0$ (Estimation))
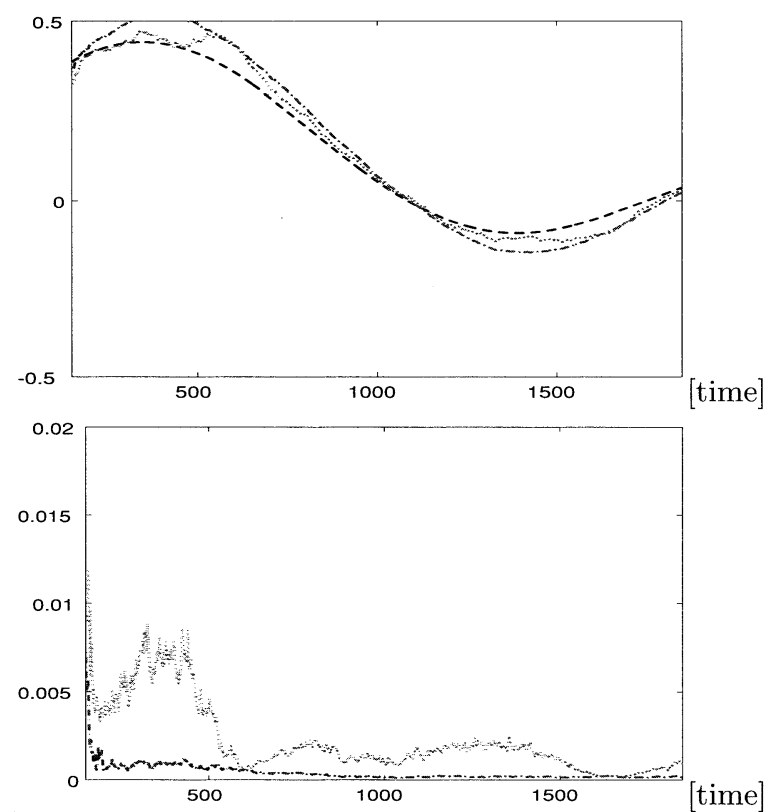

Fig. 6 Sample mean (top) and variance (bottom) of the real part of predicted conjugate poles $(N=100$, $L=150$ (150-step ahead prediction))

テムの変化の激しい時間区間 $(k=500,1500$ 周辺 $)$ で は, 予測ステップ数が増大すると多少分散は増大するも のの, 平均としてはより真值に近い值が得られることが わかる.また, Figs. 7 および 8 に $N=100, L=150$ とし, $a=1000$ と $a=500$ のつの場合について比較を 行い, 変化の速いシステムにおける効果を検証した。こ れらの結果より，加速度が一定であるとして導出したア ルゴリズムは, 変化の速いシステムの予測に有効であり, さらに予測ステップ数も大きく取れることがわかる.
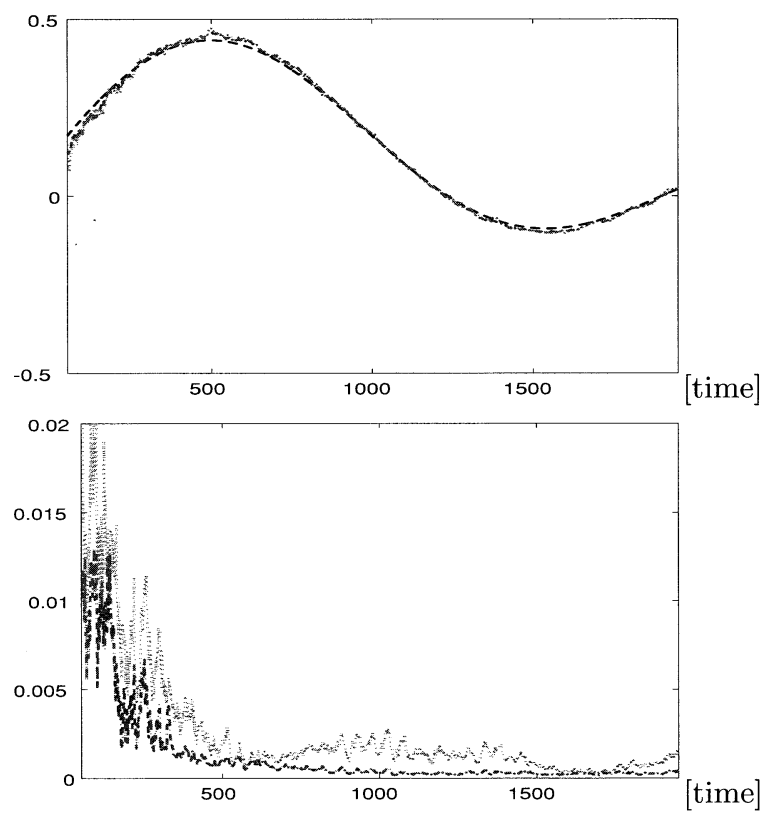

Fig. 7 Sample mean (top) and variance (bottom) of the real part of predicted conjugate poles $(N=100$, $L=150$ (150-step ahead prediction))
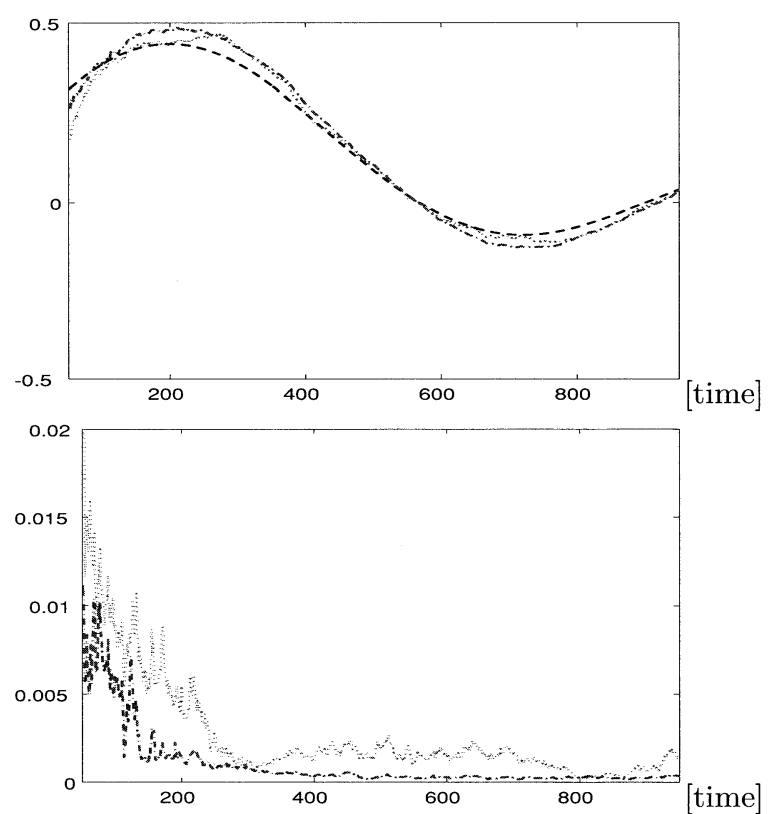

Fig. 8 Sample mean (top) and variance (bottom) of the real part of predicted conjugate poles $(N=100$, $L=150$ (150-step ahead prediction))

\section{7. 結 言}

本論文では，時変システムの未知パラメータの予測を 行うアルゴリズムについて提案し, その有効性を数值例 により検討した. 提案したシステム予測法は, 過去と現 在の二つの観測データの張る信号部分空間の間の角度を 用いて信号部分空間の回転を行う幾何学的な手法であり, 直観的である。システム予測は，予測制御には久かせな い技術になるであろうことを予想して，その逐次アルゴ リズムの導出を行い，その特性と有効性を数值例により 
確認した.

本論文で述べた予測同定法は，拡大可観測マトリクス を予測するというアイデアに基づいたものであり，それ によってシステムマトリクス $\left(A_{k}, C_{k}\right)$ の予測值は得られ るが, システムマトリクス $\left(B_{k}, D_{k}\right)$ については厳密には 予測值とはなっていない.この点さらに $\left(B_{k}, D_{k}\right)$ を積極 的に予測する方法の開発が望まれる.

なお, 本研究の一部は文部科学省科学研究費補助金 (B)-16360046の援助によって実施されたことを付記し， 謝意を表す。

\section{参 考文 献}

[1] M. Verhaegen and P. Dewilde: Subspace model identification, Part 1: The output-error state-space model identification class of algorithms; Int. J. Control, Vol. 56, No. 5, pp. 1187-1210 (1992)

[2] P. Van Overschee and B. De Moor: Subspace System Identification for Linear Systems, Kluwer Academic Pub. (1996)

[3] 片山: システム同定〜部分空間法からのアプローチ〜， 朝倉書店 (2004)

[4] 大住, 亀山, 山口: 超関数の概念を用いた連続時間確率 システムの部分空間同定法; システム制御情報学会論文 誌, Vol. 13, No. 7 pp. 338-345 (2000)

[5] A. Ohsumi, K. Kameyama and K. Yamaguchi: Subspace identification for continuous-time stochastic systems via distribution-based approach, Automatica, Vol. 38, No. 1, pp. 63-79 (2002)

[6] M. Lovera, T. Gustafsson and M. Verhaegen: Recursive subspace identification of linear and non-linear Wiener state-space models; Automatica, Vol. 36, No. 11, pp. 1639-1650 (2000)

[7] T. Gustafsson: Recursive system identification using instrumental variable subspace tracking; Proc. 11th IFAC Symp. System Identification (SYSID'97), pp. 1683-1688 (1997)

[8] Y. M. Cho, G. Xu and T. Kailath: Fast recursive identification of state space models via exploitation of displacement structure, Automatica, Vol. 30, No. 1, pp. 45-59 (1994)

[9] H. Oku and H. Kimura: Recursive 4SID algorithms using gradient type subspace tracking; Automatica, Vol. 38, No. 6, pp. 1035-1043 (2002)

[10] Y. Takei, J. Imai and K. Wada: Recursive subspace identification based on subspace extraction via Schur complement; Proc. 32nd ISCIE Int. Symp. Stochastic System Theory and Its Applications, pp. 27-32 (2000)

[11] 亀山, 松浦, 大住: 入出力デー夕量を固定した逐次部分 空間同定アルゴリズム; システム制御情報学会論文誌, Vol. 17, No. 12, pp. 517-527 (2004)

[12] K. Kameyama, A. Ohsumi, Y. Matsuüra and K. Sawada: Recursive 4SID-based identification algorithm with fixed input-output data size; Int. J. In- novational Computing \& Information Control, Vol. 1, No. 1, pp. 17-33 (2005)

[13] A. Ohsumi and T. Kawano: Subspace identification for a class of time-varying continuous-time stochastic systems via distribution-based approach; Proc. 15th IFAC World Congress, Vol. F, pp. 241-246 (2002)

[14] 奥: 逐次部分空間同定を使った変化検出法; システム 制御情報学会論文誌，Vol. 17，No. 11，pp. 506-513 (2004)

[15] M. Abdelghani, M. Verhaegen, P. Van. Overschee and B. De. Moor, Comparison study of subspace identification methods applied to flexible structures, Mechanical System and Signal Processing, Vol. 12, No. 5, pp. 679-692 (1998)

[16] W. Favoreel, B. De Moor and M. Gevers: SPC: Subspace predictive control; Proc. 14th IFAC World Congress, pp. 235-240 (1999)

[17] W. Favoreel, B. De Moor and P. Van Overschee: Subspace state space system identification for industrial processes; J. Process Control, Vol. 10, Nos. 2-3, pp. 149-155 (2000)

[18] G. H. Goulb and C. F. Van Loan: Matrix Computations, Second Edition, John Hopkins Univ. Press (1996)

\section{付録}

付録 1. 逐次アルゴリズム

現在時刻 $k_{2}=k+1$ において入出力データ $\left\{u_{k+1}, y_{k+1}\right\}$ を獲得し, 入力 /出力データの列ベクトル $u_{\alpha}(k+1)$, $u_{\beta}(k+1), y_{\alpha}(k+1)$ を構成する.このとき,データマ トリクスは

$$
\begin{aligned}
& {\left[\begin{array}{c}
U_{\alpha}(k \mid k-N+1) \vdots u_{\alpha}(k+1) \\
U_{\beta}(k \mid k-N+1) \vdots u_{\beta}(k+1) \\
Y_{\alpha}(k \mid k-N+1) \vdots y_{\alpha}(k+1)
\end{array}\right]} \\
& =\left[\begin{array}{c}
u_{\alpha}(k-N+1) \vdots U_{\alpha}(k+1 \mid k-N+2) \\
u_{\beta}(k-N+1) \vdots U_{\beta}(k+1 \mid k-N+2) \\
y_{\alpha}(k-N+1) \vdots Y_{\alpha}(k+1 \mid k-N+2)
\end{array}\right]
\end{aligned}
$$

と分割できるので, (24) 式と

$$
\begin{aligned}
& {\left[\begin{array}{c}
U_{\alpha}(k+1 \mid k-N+2) \\
U_{\beta}(k+1 \mid k-N+2) \\
Y_{\alpha}(k+1 \mid k-N+2)
\end{array}\right]=} \\
& {\left[\begin{array}{ccc}
L_{11}(k+1) & 0 & 0 \\
L_{21}(k+1) & L_{22}(k+1) & 0 \\
L_{31}(k+1) & L_{32}(k+1) & L_{33}(k+1)
\end{array}\right]\left[\begin{array}{l}
Q_{1}{ }^{\mathrm{T}}(k+1) \\
Q_{2}{ }^{\mathrm{T}}(k+1) \\
Q_{3}{ }^{\mathrm{T}}(k+1)
\end{array}\right]}
\end{aligned}
$$

を $(\mathrm{A} 1)$ 式に代入することにより，逐次形 


$$
\begin{gathered}
\hat{L}_{0}(k+1)=\hat{L}_{0}(k)+u_{\alpha}(k+1) u_{\alpha}^{\mathrm{T}}(k+1) \\
-u_{\alpha}(k-N+1) u_{\alpha}^{\mathrm{T}}(k-N+1) \\
\hat{L}_{1}(k+1)=\hat{L}_{1}(k)+u_{\beta}(k+1) u_{\alpha}^{\mathrm{T}}(k+1) \\
-u_{\beta}(k-N+1) u_{\alpha}^{\mathrm{T}}(k-N+1) \\
\hat{L}_{2}(k+1)=\hat{L}_{2}(k)+y_{\alpha}(k+1) u_{\alpha}^{\mathrm{T}}(k+1) \\
-y_{\alpha}(k-N+1) u_{\alpha}^{\mathrm{T}}(k-N+1) \\
\hat{L}_{3}(k+1)=\hat{L}_{3}(k)+u_{\beta}(k+1) u_{\beta}^{\mathrm{T}}(k+1) \\
-u_{\beta}(k-N+1) u_{\beta}^{\mathrm{T}}(k-N+1) \\
\hat{L}_{4}(k+1)=\hat{L}_{4}(k)+y_{\alpha}(k+1) u_{\beta}^{\mathrm{T}}(k+1) \\
-y_{\alpha}(k-N+1) u_{\beta}^{\mathrm{T}}(k-N+1)
\end{gathered}
$$

を得る。ここで, $u_{\alpha}(k)$ は $u_{\alpha}(k)=\left[u^{\mathrm{T}}(k-\alpha+1), \cdots\right.$, $\left.u^{\mathrm{T}}(k)\right]^{\mathrm{T}}$ である $U_{\alpha}(\cdot \mid \cdot)$ の列べクトルであり, $u_{\beta}(k)$, $y_{\alpha}(k)$ もそれぞれ同様の構造を持つ $U_{\beta}(\cdot \mid \cdot), Y_{\alpha}(\cdot \mid \cdot)$ の 列べクトルである.ただし, $U_{\beta}(k \mid k-N+1)$ の構成にあ たっては過去の入力デー夕を用い, $u_{\beta}(k)=\left[u^{\mathrm{T}}(k-\alpha-\right.$ $\left.\beta+1), \cdots, u^{\mathrm{T}}(k-\alpha)\right]^{\mathrm{T}}$ とする。また

$$
\begin{aligned}
& \hat{L}_{i}(k)=L_{i 1}(k) L_{11}^{\mathrm{T}}(k) \quad(i=0,1,2) \\
& \hat{L}_{3}(k)=L_{21}(k) L_{21}{ }^{\mathrm{T}}(k)+L_{22}(k) L_{22}{ }^{\mathrm{T}}(k) \\
& \hat{L}_{4}(k)=L_{31}(k) L_{21}{ }^{\mathrm{T}}(k)+L_{32}(k) L_{22}{ }^{\mathrm{T}}(k)
\end{aligned}
$$

である．信号部分空間を推定するためにはマトリクス の積 $L_{32}(k) L_{32}{ }^{\mathrm{T}}(k)$ が必要であるので, (A8)-(A10) 式 より

$$
\begin{aligned}
& L_{32}(k)=\left\{\hat{L}_{4}(k)-L_{31}(k) L_{21}^{\mathrm{T}}(k)\right\}\left\{L_{22}^{\mathrm{T}}(k)\right\}^{-1} \\
& L_{31}(k) L_{21}{ }^{\mathrm{T}}(k)=\hat{L}_{2}(k) \hat{L}_{0}{ }^{-1}(k) \hat{L}_{1}^{\mathrm{T}}(k) \\
& L_{22}(k) L_{22}{ }^{\mathrm{T}}(k)=\hat{L}_{3}(k)-\hat{L}_{1}(k) \hat{L}_{0}{ }^{-1}(k) \hat{L}_{1}^{\mathrm{T}}(k)
\end{aligned}
$$

が得られ，(A11)式の各辺にそれぞれの転置をかけるこ とにより

$$
\begin{gathered}
L_{32}(k) L_{32}{ }^{\mathrm{T}}(k)=\left\{\hat{L}_{4}(k)-\hat{L}_{2}(k) \hat{L}_{0}{ }^{-1}(k) \hat{L}_{1}^{\mathrm{T}}(k)\right\} \\
\cdot\left\{\hat{L}_{3}(k)-\hat{L}_{1}(k) \hat{L}_{0}{ }^{-1}(k) \hat{L}_{1}^{\mathrm{T}}(k)\right\}^{-1} \\
\cdot\left\{\hat{L}_{4}(k)-\hat{L}_{2}(k) \hat{L}_{0}^{-1}(k) \hat{L}_{1}^{\mathrm{T}}(k)\right\}^{\mathrm{T}} \quad(\mathrm{A} 1)
\end{gathered}
$$

を得る。

付録 2. 主ベクトルの満たす条件

雑音は入力と無相関であるという仮定に基づいて，信 号部分空間は $L_{b}\left(k_{2}\right)$ により

$$
\begin{gathered}
\operatorname{span}_{\mathrm{col}}\left\{L_{b}\left(k_{2}\right)\right\}=\operatorname{span}_{\mathrm{col}}\left\{\Gamma_{\alpha}\left(k_{2}\right)\right\} \\
\oplus \operatorname{span}_{\mathrm{col}}\left\{E\left(k_{2}\right)\right\}
\end{gathered}
$$

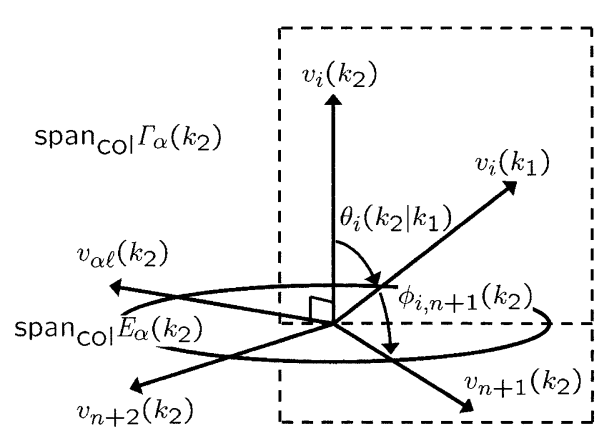

Fig. A1 Relation between signal and noise subspaces

と表現できる。ここで $\oplus$ は直和を，また $\operatorname{span}_{\mathrm{col}}\left\{E\left(k_{2}\right)\right\}$ は雑音の張る部分空間を表す。よって, $L_{b}\left(k_{2}\right)$ 列ベクト ルは

$$
\begin{aligned}
h_{j}\left(k_{2}\right) & =g_{1 j}\left(k_{2}\right) v_{1}\left(k_{2}\right)+\cdots \\
+ & g_{n j}\left(k_{2}\right) v_{n}\left(k_{2}\right)+g_{n+1 j}\left(k_{2}\right) v_{n+1}\left(k_{2}\right) \\
& +\cdots+g_{\alpha \ell j}\left(k_{2}\right) v_{\alpha \ell}\left(k_{2}\right)
\end{aligned}
$$

と表すことができる.ここで, $v_{i}\left(k_{2}\right) \in \operatorname{span}_{\text {col }}\left\{\Gamma_{\alpha}\left(k_{2}\right)\right\}$ $(i=1, \cdots, n)$ と $v_{i}\left(k_{2}\right) \in \operatorname{span}_{\mathrm{col}}\left\{E\left(k_{2}\right)\right\}(i=n+1, \cdots, \alpha \ell)$ はそれぞれ信号部分空間と雑音部分空間の主べクトルで あり (Fig. A1 参照),$g_{i j}\left(k_{2}\right)(i, j=1, \cdots, \alpha \ell)$ はこの表 現に扔ける各基底の係数である。このとき， $i$ 番目の信 号部分空間の主べクトルと $j$ 番目の雑音部分空間の主べ クトル間の角度を $\phi_{i j}\left(k_{2}\right)$ とすると, これらの関倸は

$$
\phi_{i j}\left(k_{2}\right)=\frac{\pi}{2}-\theta_{i}\left(k_{2}\right) \quad\left(0 \leq \phi_{i j}\left(k_{2}\right) \leq \pi / 2\right)
$$

となる。一方, $\operatorname{span}_{\mathrm{col}}\left\{L_{b}\left(k_{2}\right)\right\}$ の主べクトルは特異值 分解 (28) により計算でき, その際 $\operatorname{span}_{\mathrm{col}}\left\{L_{b}\left(k_{2}\right)\right\}$ と $\operatorname{span}_{\mathrm{col}}\left\{\hat{\Gamma}_{\alpha}\left(k_{1}\right)\right\}$ の角度は最小に選ばれる。すなわち $\hat{\Gamma}_{\alpha}\left(k_{2}\right)$ の主べクトルが $V\left(k_{2}\right)$ の最初の $n$ ベクトルと して計算されるためには, すべての角度 $\left\{\theta_{i}\left(k_{2} \mid k_{1}\right)\right\}$ は $\phi_{i j}\left(k_{2}\right)$ 上りも小さくなければならない.つまり

$$
\theta_{i}\left(k_{2}\right)<\phi_{i j}\left(k_{2}\right)=\frac{\pi}{2}-\theta_{i}\left(k_{2}\right) \Leftrightarrow \theta_{i}\left(k_{2}\right)<\frac{\pi}{4}
$$

の関係を満たしていなければならない. 
